\title{
Contatos Interétnicos no Vale do Araguaia: Os Iny e os Colonizadores entre os Séculos XVI e XX ${ }^{1}$
}

\author{
Ordália Cristina Gonçalves Araújo ${ }^{2}$, Elias Nazareno ${ }^{3}$
}

\begin{abstract}
RESUMO
Este artigo investiga, a partir das referências historiográficas e antropológicas, a história dos contatos estabelecidos entre os Iny ao longo da colonização do território brasileiro, com ênfase à forma como os Javaé interagiram com os colonizadores no decorrer da ocupação territorial da região central do Brasil, entre os séculos XVI e XX. A partir das bandeiras que atravessaram "os sertões do Paraupava", analisouse a história dos contatos interétnicos entre os Javaé e os colonizadores, buscando, desde uma análise documental e bibliográfica, a perspectiva decolonial, o ponto de vista Javaé inserido nessa literatura. Assim, espera-se contribuir ao entendimento do protagonismo e da postura isolacionista desse povo no interior da Ilha do Bananal em praticamente todo o século XIX como resistência a esses contatos.
\end{abstract}

Palavras-chave: contatos interétnicos; Rio Araguaia; povo Javaé.

\footnotetext{
10 artigo está baseado em grande parte na tese "Os Javaé e o protestantismo: salvação e resistência (1896-1937)", defendida em 2019 no Programa de Pós-Graduação em História da Universidade Federal de Goiás por Ordália Cristina Gonçalves Araújo e orientada por Elias Nazareno. 2 Doutora em História (Universidade Federal de Goiás), Professora de Didática e Metodologia do Ensino de História e Estágio Curricular Supervisionado (Universidade Estadual de Goiás), ORCID: https://orcid.org/0000-0002-7585-0320, e-mail: ordalia_c@hotmail.

${ }_{3}$ Doutor em em Sociologia (Universidade de Barcelona), Pós-doutor em Sociologia (Unversidade de Barcelona) e em Antropologia Social (Universidade de Brasília), Professor Associado I no Programa de Pós-graduação em História e no Curso de Educação Intercultural para a formação de Professores Indígenas (Universidade Federal de Goiás), Professor Visitante (Universidade de Jujuy, Argentina), ORCID: https://orcid.org/0000-0002-9689-9721, e-mail: eliasna@hotmail.com.
} 


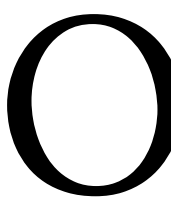

Vale do Araguaia se constitui numa região marcada por fronteiras ${ }^{4}$ étnicas, ambientais, cosmológicas, culturais e tantas outras. Percebe-se uma trajetória de continuidades e descontinuidades em relação aos contatos e às próprias fronteiras estabelecidos entre os não indígenas e os Javaé em distintos períodos ao longo da colonização do Vale do Araguaia, seja durante as expedições sertanistas ao Brasil Central antes dos aldeamentos ou, depois deles, com os projetos integracionistas. Pretende-se, nesse artigo, analisar essa trajetória desde uma pesquisa documental (fontes orais e escritas) e bibliográfica com ênfase aos Iny Javaé, um povo até recentemente invisibilizado no meio acadêmico por ser considerado um "subgrupo Karajá", referência recentemente contestada por eles, dado que esses últimos, histórica e cosmologicamente, são vistos como ixĩju ou estrangeiros.

Os estudos historiográficos e antropológicos são cotejados com as fontes orais e escritas na análise da história dos contatos estabelecidos entre os Iny ao longo da colonização do território brasileiro no decorrer dos séculos XVI e XX, buscando perceber a forma como os Javaé interagiram com os não indígenas desde então.

Os contatos entre os Iny e os colonizadores aconteceram antes e depois de 1778, tornaram-se dramáticos no contexto da expansão colonial, motivo pelo qual os Javaé preferiram refugiar-se no interior na Ilha do Bananal, para retomar, a partir do final do século XIX, uma nova fase de contatos com os não indígenas. Por isso, a noção de contato como um evento repetitivo e cotidiano ${ }^{5}$ nos auxilia na compreensão da história dos contatos entre os Javaé e os colonizadores.

Outra característica dos contatos é que eles se constituem eventos anunciados em muitas narrativas indígenas de fundação do mundo, incluindo as próprias narrativas Javaé. Nelas, existe a noção de que a chegada do não indígena representa "o retorno de um irmão que foi embora há muito tempo, e que indo embora se retirou também no sentido de humanidade", que se estava a construir. ${ }^{6}$

\footnotetext{
${ }^{4}$ Sandro Dutra e Silva; Altair Sales Barbosa, "Paisagens e fronteiras do Cerrado: ciência, biodiversidade e expansão agrícola nos chapadões centrais do Brasil", Estudos Ibero-Americanos 6, 1 (jan.-abr. 2020): 1-18.

${ }^{5}$ Ailton Krenak, "O eterno retorno do encontro". In: Adauto Novaes (org.), A Outra Margem do Ocidente (São Paulo, Companhia das Letras, 1999), 25-27.

${ }^{6}$ Krenak, "O eterno retorno do encontro", 25-27.
} 
Para os Javaé, essa origem é narrada na história de criação do mundo quando muitos povos saíram do nível subaquático para o nível terrestre. ${ }^{7}$

A origem do indígena e do não indígena de uma única fonte fundadora e a própria história dos contatos como parte de um evento anunciado pressupõem uma história na qual o indígena é o agente e não a vítima ao longo de todos os acontecimentos relativos aos contatos interétnicos. ${ }^{8} \mathrm{O}$ protagonismo Javaé, ${ }^{9}$ se torna perceptível durante sua "pacificação" e no isolamento no interior da Ilha do Bananal, na segunda metade do século XVIII e XIX, respectivamente. Mas o que dizer deles em períodos anteriores? Posto isso, fez-se um retorno à bibliografia que remonta às primeiras expedições sertanistas no Vale do Araguaia.

Em função da grande quantidade das expedições militares ${ }^{10}$ que, já do século XVI percorriam o território recém-descoberto, fez-se um recorte em relação àquelas que atravessaram "os sertões do Paraupava", posteriormente sertão do Goiás, dando especial ênfase às que se aproximaram ou percorreram a região do rio Araguaia, entrando em contato com os indígenas que nela habitava, sobretudo os Iny (Karajá e Javaé), apresando-os inúmeras vezes. Posteriormente, trata-se da história dos contatos interétnicos entre os Javaé e os colonizadores, com ênfase à perspectiva Javáe, posto o embasamento decolonial ${ }^{11}$ nesse artigo ao visibilizar as narrativas Iny. São narrativas encontradas na tese de doutoramento de Patrícia de Mendonça Rodrigues (2008), a primeira pesquisa antropológica que aborda de maneira ampla a totalidade cosmológica Javaé.

O uso do termo decolonial (ou intercultural crítico) se faz em múltiplas dimensões: implica em reconhecer os impactos provocados pela colonialidade ${ }^{12} \mathrm{e}$,

\footnotetext{
${ }^{7}$ Patrícia de Mendonça Rodrigues, “A caminhada de Tanyxiwé: uma teoria Javaé da História”, (Tese de doutorado, Chicago, 2008), 47-99.

${ }^{8}$ Manuela Carneiro da Cunha, Introdução a uma história indígena, In: História dos índios no Brasil (São Paulo: Cia das Letras, Secretaria Municipal de Cultural: FAPESP, 1992), 18-19.

${ }_{9}^{9}$ Patrícia Emanuelle Nascimento. Protagonismo indígena na capitania de Goiás e suas estratégias e atuações frente às políticas indigenistas no século XVIII (Tese de Doutorado em História, Universidade Federal de Goiás, Goiânia, 2019).

${ }^{10}$ Conhecidas como bandeiras, as expedições militares constituiam milícias que adentravam as regiões interioranas no novo território. Além de formação, armamentos, tambores e caixas, elas dispunham de um escrivão que redigia o testamento dos sertanistas à iminência de morrer. Cf. Manoel Rodrigues Ferreira, O mistério do ouro dos martírios: desvendando o grande segrêdo das bandeiras paulistas (São Paulo, Editora Biblos, 1960), 154 e 172.

${ }^{11}$ Catherine Walsh (Org), "Pedagogías decoloniales: Prácticas insurgentes de resistir, (re)existir y (re)vivir", (Quito-Ecuador: Ediciones Abya-Yala. Serie Pensamiento decolonial, 2013); Elias, Nazareno, "História, tempo e lugar entre o povo indígena Bero Biawa Mahãdu (Javaé): a partir da interculturalidade crítica, da decolonialidade e do enfoque enactivo", In: Marcos de Jesus Oliveira (Org.), Direitos humanos e pluriversalidade: conexões temáticas, (Curitiba: Editora Prismas Ltda, 2017).

12 A colonialidade, articulada ao padrão mundial de poder, é parte constitutiva do que se convencionou denominar por modernidade e está entrelaçada à conquista da América, desdobrando-se em uma estrutura complexa de níveis entrelaçados perceptíveis na colonialidade do ser, do
} 
simultaneamente à ela revelar as estratégias de resistência por parte de povos como os indígenas, continuamente submetidos aos projetos civilizadores de subalternização de suas epistemologias, ao tempo em que se pretende ressaltar seus conhecimentos, ainda que mediados pela academia.

\section{OS JAVAÉ E O RIO ARAGUAIA}

Karajá, Javaé e Xambioá constituem os três grupos indígenas formadores do povo Iny (gente) e habitam, desde o século XVI, pelo menos, a região do Vale do Araguaia. ${ }^{13}$

Os Javaé se autodenominam Itya mahãdu ou Povo do Meio por compreenderem que habitam a região intermediária do cosmos composto por três mundos. Simbolicamente, o cosmos é associado a um grande corpo, cujas extremidades equivalem, por um lado, à cabeça como correspondente do leste, do rio acima (ibòkò) onde estão as cabeceiras do rio. Seria o nível celeste e superior (Biu Mahãdu). E por outro, aos pés em referência ao oeste, ao rio abaixo (iraru), lugar da foz do rio, considerado o nível subaquático e inferior (o Berahatxi) (RODRIGUES, 2004, p. $24 ; 2008$, p. 47).

As duas extremidades do rio constituem, na cosmologia Javaé, "as polaridades do principal eixo espacial e cosmológico, relacionados respectivamente ao começo e ao fim da vida, ao nascente e ao poente" (RODRIGUES, 2005, p. 134). No nível intermediário desses dois extremos está situada a Ilha do Bananal, o mundo terrestre o Ahana Òbira ou Face de Fora, lugar de habitação dos Javaé quando estes saíram do Berahatxi.

saber, do ver, do fazer e do pensar e tantas outra. Cf. Aníbal Quijano, "Colonialidade do poder e classificação social", In: SANTOS, Boaventura Souza; MENESES, Maria Paula. (Org.). Epistemologia do Sul (São Paulo: Cortez, 2010); Walter Mignolo, Desobediência epistêmica: retórica de la modernidad, lógica de la colonialidad y gramática de la descolonialidade. (Argentina, Ediciones del Signo, 2010); Nazareno, "História, tempo e lugar....

13 Os Karajá, vivem no médio e no alto curso do rio Araguaia e os Karajá Xambioá ou Karajá do Norte estão no baixo curso do Araguaia, na Terra Indígena Xambioá, que fica no norte do Tocantins, município de Santa Fé do Araguaia. Cf. André Toral, "Cosmologia e sociedade Karajá", (Dissertação de Mestrado, Programa de Pós-Graduação em Antropologia Social, Museu Nacional, Universidade Federal do Rio de Janeiro, Rio de Janeiro, 1992), 14-23. 
Por isso, eles também se autodenominam Ahana Òbira Mahãdu ("O Povo de Fora" ou "O Povo com a Face de Fora"). Dessa maneira, o referencial espacial para os Iny é o rio Araguaia e seus tributários, expressados pelos conceitos relacionais de "rio acima" (ibòko) e "rio abaixo" (iraru), respectivamente, "sul" e "norte" do ponto de referência, conforme explicação acima, delimitando, em função disso, o ordenamento sócio-espacial das aldeias. ${ }^{14}$

Além desse ordenamento, com implicações diretas na referência à construção das aldeias, para esse povo o rio assume diversas funções: torna-se o elo entre a aldeia e seu entorno, o lugar de subsistência familiar e de diversas práticas comunitárias cotidianas (como nas tarefas domésticas e educativas) e, sobretudo, lugar de conhecimento cosmológico. ${ }^{15}$

O território de ocupação secular dos Javaé compreende tanto o interior da Ilha do Bananal (Iny Òlòna, o lugar de onde saíram os humanos ou Ijata Òlòna, lugar de onde surgiram as bananas) como a porção adjacente a ela, fora da Ilha, inserida na região da bacia do Rio Javaés. Os Javaé habitam a sua parte oriental formada a oeste pelo rio Javaés (Bero Biawa, o "Rio Companheiro" do Araguaia, também conhecido como "braço menor" do rio Araguaia ou "Furo do Bananal").

Nomeada de Ilha de Sant'Anna em 1775 pelo Alferes Pinto da Fonseca, a Ilha do Bananal, está situada no médio curso do Araguaia, ${ }^{16}$ o Berohokỹ - "o Grande Rio", cuja nascente situa-se na Serra do Kaiapó. Inicialmente denominado pelos paulistas de Rio Paraupava, o Araguaia está inserido, junto com o rio Tocantins, na Bacia Amazônica. Nasce no município de Mineiros em Goiás e contém a maior ilha fluvial do mundo. Ao longo de seus $2.627 \mathrm{~km}$ de extensão, esse rio atravessa e divisa estados como Goiás e Mato Grosso, Tocantins e Mato Grosso, Tocantins e Pará.

Localizado na região central do atual território brasileiro, o rio Araguaia constitui-se em um lugar de passagem de diversas expedições europeias de cunho militar e religioso desde o final do século XVI, oriundas de dois cenários de partida, do

\footnotetext{
14 Patrícia de Mendonça Rodrigues, "Vida Cerimonial e luto entre os Javaé", Revista de Estudos e Pesquisas 3, 1/2 (jul./dez. 2006), 29 e 109.

15 Nathalia Cunha Polese, "Crianças indígenas da aldeia Canuanã (Formoso do Araguaia - TO): relação entre cultura, infância e educação", (Dissertação de Mestrado, Universidade do Estado de Minas Gerais, Programa de Pós-graduação em Educação, 2014); Lázaro Lopes Rosário Tapuio, "A importância do rio Javaé para o povo Javaé", (Projeto Extraexcolar, Universidade Federal de Goiás, Goiânia, 2011).

${ }^{16}$ A parte do rio Araguaia entre a cidade de Aruanã, onde está a foz do rio Vermelho, e a cidade de Araguacema, antigo Presídio de Santa Maria. Cf. Rodrigues, "A caminhada de Tanyxiwé...", 27.
} 
sul, especialmente de São Vicente (São Paulo) e da Amazônia Portuguesa, buscando encontrar jazidas de metais preciosos e apresar indígenas. ${ }^{17}$ Ocasiões em que os bandeirantes deparavam, inevitavelmente, com inúmeros povos indígenas, dentre eles, os Iny. ${ }^{18}$

Provavelmente, em um período anterior a 1500, eles tenham-se movimentado do eixo mais baixo do rio (norte para nós e sul para os Javaé), próximo à sua foz no Tocantins, em direção ao seu alto curso (sul para nós e norte para os Javaé), provocando a dispersão desse povo em vários grupos que se fixaram em distintas regiões ao longo do Araguaia, incluindo a Ilha do Bananal. Atualmente, o maior índice populacional dos povos Iny encontra-se localizado nessa ilha no Parque Indígena do Araguaia. ${ }^{19}$

\section{O SERTÃo Do PARAUPAVA NOS SÉCULOS XVI E XVII}

As trilhas indígenas configuravam caminhos que interligavam todo o continente, do interior ao litoral, em uma grande rede de comunicação. ${ }^{20}$ Muitos sertanistas usavam tais roteiros em suas excursões pelo interior.

Ao longo dos séculos, o aperfeiçoamento dos roteiros ${ }^{21}$ sertanistas descortinou para os portugueses - colonizadores ou missionários - os aspectos físicos e geográficos das imensas regiões exploradas. Motivadas pela lenda do Paraupava, as bandeiras cumpriram para a Coroa Portuguesa a função de descortinar o ambiente encontrado, averiguar a veracidade das histórias surgidas e elaboradas a partir dos contatos feitos com os indígenas e contribuir para a execução mais nítida dos mapas cartográficos da região, incluindo as bacias hidrográficas, seus rios e afluentes.

\footnotetext{
17 Paulo Bertran, História da terra e do homem no Planalto Central. Eco-história do Distrito Federal: do indígena ao colonizador (Brasília, Editora Verano, 2000), 45; Luís Palacin, "Política pombalina em Goiás - contrastes", Revista do ICHL (1982): 60; Mary Karasch, Before Brasília: Frontier Life in Central Brazil (University of New York Press, 2016), 64-69.

18 Rodrigues, "A caminhada de Tanyxiwé...", 68-70; Luiz Antonio da Silva e Sousa, "Memoria sobre o descobrimento, governo, população, e cousas mais notaveis da Capitania de Goyaz", Revista Trimensal de Historia e Geographia ou Jornal do Instituto Historico e Geographico Brasileiro XII (4º trimestre de 1849, 2ª . edição 1872), 494-496; Marivone Matos Chaim, Aldeamentos indígenas: Goiás (1749-1811) (São Paulo, Nobel, 1983), 52-53.

19 Cf. Toral, "Cosmologia e sociedade Karajá"..., p. 14; Maria do Socorro Pimentel da Silva, Impactos da educação na vitalidade patrimônio epistêmico Iny, (Goiânia, Kelps, 2015): 14.

${ }^{20}$ Ferreira, O mistério do ouro dos martírios..., 156, 189, 197.

${ }^{21}$ Os roteiros eram os caminhos traçados pelos sertanistas para se chegar a uma mina, com ênfase nos acidentes geográficos mais evidentes ao longo do seu percurso. Cf. Ferreira, O mistério do ouro dos martírios..., 53.
} 
Contribuição efetivada sob o duplo interesse: a busca de metais preciosos e o apresamento de mão de obra indígena, a ser levada para o trabalho no litoral.

A lenda do Paraupava tem início logo a partir de 1500, quando portugueses e espanhóis, em contato com indígenas do litoral, ouvem destes notícias de uma grande lagoa, rica em metais preciosos (ouro e prata), em torno da qual se encontravam diversos povos indígenas e de onde nasciam todos os principais rios do então território descoberto. A "notícia do lago chegou em 1549, via interrogação que fez o governador-geral Tomé de Souza aos índios". ${ }^{22}$

A crença na existência desse lugar motivou por séculos as inserções de portugueses e espanhóis pelo interior na busca da referida lagoa, que, em virtude da diversidade linguística indígena, receberia diversas denominações, dentre elas Lagoa Paraupava, Lagoa Vupabuçu, Lacus Eupana, Lago Xaraiés, Lago Dourado, Lagoa do Ouro, Lagoa Grande ou Alagoa Grande e Laguna del Paytit.

Já na primeira metade do século XVII, o mito já havia sido desmistificado pelos sertanistas de São Paulo, em decorrência da comprovação da inexistência da Lagoa como origem de todos os rios brasileiros. Nas cartas geográficas percebe-se então a mudança com a identificação, independente dos rios, e a substituição da lagoa pela ilha Paraupava.

Entre 1596 a 1618, quatro expedições ${ }^{23}$ saíram de São Paulo em direção ao sertão do Paraupava ${ }^{24}$, como era conhecida a região do rio Araguaia nesse período. ${ }^{25}$ Coube à expedição de Martim Rodrigues Tenório de Aguilar (1608-1613) apresar indígenas Carajaúnas, da Ilha dos Carajúnas ou Carajaúnas, termo que aponta para os indígenas Karajá e à Ilha do Bananal. Embora fosse perceptível aos sertanistas que tais indígenas se comunicavam numa língua distinta da geral (tupi), seis deles foram apresados e levados à vila de São Paulo de Piratininga. Possivelmente, entre eles estariam indígenas Javaé, visto que, até o início do século XX, Karajá e Javaé eram

\footnotetext{
22 Paulo Bertran, "As primeiras descobertas dos cerrados centrais", Revista Humanidades 8, 2 (1992), 233.

${ }^{23}$ São elas: Domingos Rodrigues (1596-1600), Domingos Luís Grou e de Antônio Macedo (1590-93), Martim Rodrigues Tenório de Aguilar (160813) e André Fernandes (1613-15).

24 O termo "Paraupava" havia aparecido pela primeira vez na história do bandeirismo paulista no contexto da expedição de Domingos Luís Grou e de Antônio Macedo (1590-1593), como "uma denominação geográfica que a partir daí se incorpora à história da Vila de São Paulo". Cf. Manoel Rodrigues Ferreira, As bandeiras do Paraupava (São Paulo, Prefeitura Municipal, 1977), 76.

${ }^{25}$ Ferreira, O mistério do ouro dos martírios...; Bertran, "As primeiras descobertas dos cerrados centrais"..., 45-47.
} 
considerados o mesmo povo, ${ }^{26}$ algo que vem sendo refutado pelos segundo atualmente.

André Fernandes foi o sertanista responsável por encontrar ouro no rio Araguaia durante a expedição que comandava entre 1613 e 1615. Contudo, o que marcou essa bandeira foram os conflitos que tiveram às margens do Araguaia com os indígenas da região, resultando em baixas de ambos os lados, e a contribuição cartográfica que possibilitou a desmistificação do mito da lagoa Dourada, por conta dos detalhes da expedição, amplamente que divulgada em Portugal e utilizada pelos $\operatorname{cosmógrafos}^{27}$, dada a amplitude dos registros levado a cabo pelo jesuíta Antônio Araújo. $^{28}$

Residente em São Paulo e embasado em informações de sertanistas, esse padre acreditava ser "possível uma ligação terrestre entre a vila de São Paulo e Belém do Pará, o que seria de muita conveniência para a Companhia de Jesus, pois colocaria aquelas missões do Grão-Pará em comunicação com as da Capitania de São Vicente, por terra". Para além da divulgação dos resultados, Antônio Araújo interessava-se em uma possível evangelização dos povos indígenas habitantes do rio Paraubava e da Ilha dos Caraiaúnas. Ele considerava que os índios aprisionados e levados para o litoral pela expedição de André Fernandes (1613-1615) facilmente guiariam os jesuítas, visto que os padres não iriam para "guerrear ou cativar, mas a converter e libertar".29

Entre 1590 até 1618, na fase de "investigações primárias" dessa região "tanto o Brasil Central quanto boas porções de Minas Gerais foram amplamente conhecidas e transitadas pelas primeiras expedições da história de São Paulo". ${ }^{30}$

De 1618 até 1648 ocorre um hiato nas expedições que têm como ponto de partida a Vila de São Paulo, finalizando o "ciclo Paraupava" (1589-1618). Se expedições oriundas de São Paulo ocorreram, como de fato devem ter ocorrido, não foram

\footnotetext{
${ }^{26}$ Fritz Krause. "Nos sertões do Brasil", Revista do Arquivo Municipal 73-74 (1940-43): 188.

27 Os cosmógrafos eram produtores de mapas e globos, autores de tratados cosmográficos que estavam vinculados ao conhecimento teórico e sistemático. Cf. Andréa Doré, "América Peruana e Oceanus Peruvianus: uma outra cartografia para o Novo Mundo", 20 (Outubro 2014): 6.

${ }^{28}$ Bertran, História da terra e do homem no Planalto Central..

${ }^{29}$ Ferreira, O mistério do ouro dos martírios..., 229, 239.

${ }^{30}$ Bertran, História da terra e do homem no Planalto Central..., 51.
} 
registradas. Contudo, este período influenciou diretamente a mudança do nome do rio Paraupava para rio Araguaia em meados do século XVII. ${ }^{31}$

Dessa forma, a não ocorrência de bandeiras paulistas indo ao sertão do Paraupava por volta de três décadas da primeira metade do século XVII provocou certo esquecimento da localização e características do mencionado rio entre esses sertanistas. O resultado foi, já em meados desse mesmo século, a mudança do nome Paraupava, conforme era conhecido, para Araguaia, de acordo com as expedições jesuíticas que tiveram como cenário de partida Belém do Pará, instigadas pelo relato jesuítico.

Foi representando Belém do Pará que em 1646, Bartolomeu Barreiros de Ataíde entregaria ao Rei, em Lisboa, uma representação no intuito de "dar notícia do descobrimento de uma mina de ouro e alvitrar outras de que tenho notícia, de diferentes metais". ${ }^{2}$ A mina encontrada localizava-se no território da "nação do gentio Carajáputangas", denominada de Província dos Carajá-putangas. Para se chegar até ela, saindo de Belém do Pará, fazia-se o percurso em canoas passando pela Província dos Tocantins, onde vivia "gentio de paz", até a Província do Araguaia, "onde está a grande mina" e, segundo notícias de sertanistas e de indígenas, existiam outras, incluindo minas a serem descobertas em diversas localidades da região.

Os moradores da Província do Araguaia era "gente belicosa" e, apesar da ferocidade, Bartolomeu Barreiros de Ataíde deixava claro que havia estabelecido com eles uma relação pacífica, diferentemente de outros portugueses. Estes, por sua vez, teriam ido a essas minas em tempos anteriores, não especificado por Bartolomeu, e retirado ouro.

Bartolomeu Barreiros de Ataíde julgava importante afirmar que nenhum português se dispusera ao empreendimento da exploração das ditas minas localizadas na região do Araguaia, sendo ele o primeiro de Belém do Pará a fazê-lo. Com esses argumentos, ele pretendia obter do rei a aprovação de uma grande bandeira visando 
explorar as minas de ouro do Araguaia, pois, segundo acreditava, tratava-se de uma região fronteiriça ao Peru, tendo ouro, portanto. ${ }^{33}$

Surpreendentemente, o Conselho Ultramarino deliberou puni-lo sob informações de excessos cometidos por ele contra os indígenas encontrados durante a expedição que fizera à região do Araguaia anos antes na forma de prisões, mortes e outras violências e, claro, desrespeito ao regimento que ditava o contrário. Bartolomeu Barreiros de Ataídes fora o primeiro sertanista de Belém do Pará a subir o Tocantins a fim de chegar às minas de ouro, próxima da localidade onde os Karajá viviam, no ano de 1644, e protagonizara um dos muitos episódios dramáticos envolvendo a história da expansão colonial no Brasil: a violência contra o indígena, incluindo o povo Iny.

Da Capitania do Pará, desde então, sertanistas e jesuítas iniciaram um intenso movimento de exploração do Tocantins e do Araguaia, contíguo, doravante, à retomada das entradas paulistas rumo ao interior. Tal é o caso da bandeira de Raposo Tavares (1648-1651) que partiu da Vila de São Paulo com o intuito de descobrir e lavrar minas de ouro do Araguaia, guiado pelo roteiro deixado por André Fernandes (16131615).

As informações relacionadas à região do Araguaia nesse período advêm dos integrantes da Companhia de Jesus instalada no Grão-Pará, considerado, por isso, como o "ciclo jesuíta" (1653-1721). Em 1636, o padre Luiz Figueira subiu o Tocantins para visitar aldeias indígenas e acabou por chegar ao rio Araguaia. Todavia, o marco da inserção jesuítica no planalto central seria 1653, com as expedições ao Tocantins e Araguaia por diversos padres sob a supervisão de Antônio Vieira (1608-1697) ${ }^{34}$, sendo perceptível a confluência de interesses coloniais dos sertanistas e dos missionários advindos de São Paulo e do Grão-Pará, respectivamente.

Se os jesuítas dominaram as informações do rio Araguaia em meados do século XVII, os paulistas retomam as bandeiras saindo de São Paulo para o sertão dos

\footnotetext{
33 Desde 1590, o conhecimento geográfico europeu a respeito do continente sul-americano tinha como referencial o protagonismo das minas do Peru. A partir dessas minas, projetava-se uma expectativa de encontrar minas auríferas em outras regiões do continente como a do Brasil Central. Cf. Doré, "América Peruana e Oceanus Peruvianus...: 5.

${ }^{34}$ As expedições jesuítas são: Antônio Vieira, Francisco Veloso, Francisco Veloso, Antônio Ribeiro e Manuel de Sousa (1653) [Marivone Matos Chaim, Aldeamentos indígenas: Goiás (1749-1811) (São Paulo, Nobel, 1983), p. 19]; Missão Carajá liderada por Tomé Ribeiro (1655); Tomé Ribeiro e Ricardo Caréu (1658); Manoel Nunes (1659); Gaspar Misch e João Almeida (1668) ; Gonçalo de Veras e Sebastião Teixeira (1671).
} 
Guaiás a partir de $1665^{35}$. As várias expedições desse período confirmam a existência de um caminho terrestre bastante conhecido de São Paulo ao sertão de Goiás, frequentado por inúmeros sertanistas desejosos de encontrar ouro e apresar indígenas.

Com a retomada dos caminhos para o interior, as expedições paulistas desse período configuram o "Ciclo Sertão dos Goiás". ${ }^{6}$

Em decorrência dessas excursões e a sua consequente publicização a partir de 1630, a cartografia portuguesa passou por transformações substanciais, efetivada nos mapas produzidos pelos cosmógrafos da Coroa. Se antes predominava a concepção da existência de uma lagoa rica em minérios preciosos no interior do território, posteriormente foi possível superar tal perspectiva em decorrência das costumeiras expedições sertanistas. Mais do que isso, nas expedições paulistas ou jesuíticas, os Iny entravam em contato com os colonizadores, fossem os sertanistas ou os missionários, tornando-se alvo dos interesses de ambos: escravidão ou evangelização.

\section{EXPANSÃO COLONIAL E ALDEAMENTOS}

Ao findar o século XVII, "o território goiano era suficientemente conhecido, tanto por gente de São Paulo como de Belém, e os caminhos de penetração se achavam descritos nos roteiros que corriam de mão em mão"37. No limiar do século XVIII, portanto, tem-se a corrida do ouro em decorrência da descoberta de jazidas de metais preciosos em Sabará - rio das Velhas (Minas Gerais), na última década do século XVII (1694); em Cuiabá (Mato Grosso), em 1719; e, finalmente, nas Minas dos Goyazes (1722-1725), como o território goiano ficou conhecido por quase um século. Foi o início da colonização do Brasil Central ${ }^{38}$ apesar das correrias das bandeiras por sertões adentro.

\footnotetext{
35 Nesse período as expedições foram a de Francisco Lopes Buenavides (1665-1666); de Antônio Pais (1671), de Luís Castanho de Almeida (1671) e de Sebastião Pais de Barros (1673).

${ }^{36}$ Carlos Christian Della Giustina, "Degradação e Conservação do Cerrado: uma história ambiental do estado de Goiás" (Brasília, s/e., 2013$), 92$.

${ }^{37}$ Chaim, Aldeamentos indígenas..., 20.

${ }^{38}$ Bertran, "As primeiras descobertas dos cerrados centrais"..., 20.
} 
A descoberta de ouro nas Minas dos Goyazes constitui-se em um acontecimento ocorrido em decorrência da expedição de Bartolomeu Bueno da Silva, João Leite da Silva Roriz e Domingues Rodrigues do Prado, em 1720, quando saem da Vila de Santana de Paranaíba, vindo a encontrar ouro às margens do Rio Vermelho, local no qual se instalou a Vila de Sant'Anna, em 1726. Desde então, inúmeros outros bandeirantes deixaram o litoral provocando uma corrida para o interior, no sentido de encontrar outras jazidas de ouro.

Era o início do processo de povoamento da região por parte da população não-indígena e, consequentemente, da sociedade goiana, à custa do apresamento de populações indígenas, que chegariam até mesmo ao aniquilamento completo ou parcial, por conta dos contatos assimétricos com europeus e paulistas desde o processo de colonização, iniciado no século XVI. Tal foi o caso dos Goyá, ${ }^{39}$ dos Crixá, dos Kayapó do Sul e dos Akroá, extintos ou migrados para outras regiões logo após os primeiros contatos com os colonizadores.

Encontrar ouro provocou uma efervescência populacional em torno das regiões onde esse mineral pudesse existir, constituindo núcleos populacionais restritos a esses lugares, à custa, muitas vezes, do despovoamento de capitanias como Rio de Janeiro, Pernambuco e Bahia; e, até mesmo, de regiões de Portugal, em virtude da intensa procura pelas regiões mineradoras. ${ }^{40}$ Todavia, em seu conjunto, na região ao redor dos veios mineradores continuava um vazio de população não-indígena.

Ao tempo em que o ouro se esgotava, os mineiros mudavam-se para outro lugar, resultando na diminuição do contingente populacional e, no limite, no desaparecimento do núcleo populacional ali iniciado. O resultado, muitas vezes, era o surgimento de vários arraiais na região, não mais pautados pela descoberta de minério valioso, mas da ocupação de extensas áreas territoriais com vistas à formação de imensas fazendas de pastoreio.

Destarte, era fundamental o processo de "assimilação" dos diversos povos indígenas com foco na liberação do território necessária à expansão colonial. A

\footnotetext{
${ }^{39}$ Bertran conjectura que este povo seja Tupi em virtude da etimologia do termo Goyá. Caso não seja, poderia constituir-se em um ramo Karajá "da bacia do rio Vermelho onde todos os sítios arqueológicos já pesquisados levam a marca Carajá" Cf. Bertran, História da terra e do homem no Planalto Central..., 231.

40 Chaim, Aldeamentos indígenas..., 22.
} 
assimilação "supõe a mudança cultural de um povo supostamente inferior no sentido de adotar a cultura alegadamente superior de um poder colonial", ${ }^{41}$ devendo se efetivar nos aldeamentos.

Inserida nos planos da Metrópole portuguesa, a política de fundação dos aldeamentos buscava resolver a questão do povoamento por meio da expansão colonizadora encampada por garimpeiros e mineradores. Constituída de duas fases, ela foi adotada em Goiás em meados do século XVIII, a partir de uma "adaptação dos ideais anteriormente defendidos pelos jesuítas e colonos". ${ }^{4}$

A primeira fase compreende o período de 1749-1772 e foi marcada, logo no início do governo de D. Marcos de Noronha (1749-1755), o Conde dos Arcos, pelo aldeamento dos Akroá e Xacriabá em São José do Duro e em Formiga, abandonado pelos indígenas em 1757; pelo uso dos indígenas mansos como mecanismo para apresar os indígenas selvagens, a exemplo da presença dos Bororo na expedição de Antônio Pires de Campos contra os Kayapó (1742); pela determinação do Directório que se deve observar nas Povoações dos Índios do Pará e Maranhão (1757-1798) ${ }^{43}$, como novas diretrizes para o relacionamento entre colonizadores e indígenas em toda a Colônia; e, por fim, pelas orientações da Coroa a favor da guerra ofensiva contra os indígenas por causa das contínuas hostilidades entre os Xavante, no norte, e os Kayapó, no sul, contra os colonizadores.

A segunda fase compreende o período que se estende desde 1772 - com o governo de D. José de Almeida Vasconcellos, posteriormente Barão de Mossâmedes (1772-78) - até o final do século XVIII, com o revigoramento do sistema de aldeamento que havia estagnado desde o governo de D. Marcos de Noronha. Mais especificamente a partir da metade da administração do barão de Mossâmedes, "será aplicada de forma efetiva e sistemática a política pombalina. A partir desse momento começa-se a

\footnotetext{
${ }^{41}$ Mary Karasch, Catequese e cativeiro: política indigenista em Goiás, 1789-1889. In: Manuela Carneiro da Cunha, História dos índios no Brasil (São Paulo, Companhia das Letras, Secretaria Municipal de Cultura/FAPESP, 1992), 401.

42 Chaim, Aldeamentos indígenas..., 79.

43 Publicado em 3 de maio de 1757, o Directório foi confirmado como novas diretrizes para a Colônia pelo Alvará real em 17 de agosto de 1758. Em Goiás as novas medidas chegaram em 18 de outubro de 1758 durante do governo de João Manuel de Melo (1758-70). Trata-se de um Regimento composto de 95 parágrafos para orientar os Diretores a tratarem os indígenas nos aldeamentos independentes, aqueles administrados pelos Diretores e não pelos Juízes Ordinários, nos casos em que os aldeamentos se transformassem em povoações. Os Diretores teriam função apenas diretiva e não coercitiva, sendo sua função principal a "civilização" dos indígenas. Deveriam observar os seguintes itens: introduzir a língua falada na Metrópole nos aldeamentos em contraposição ao uso da língua geral, as povoações deveriam possuir escolas públicas, escolher sobrenomes para os indígenas, persuadi-los a usar roupas, organizá-los em casas semelhante às dos não-indígenas, fiscalizar o comércio dos produtos agrícolas cultivados pelos próprios indígenas. A vigência do Directório foi até 12 de maio de 1798. Cf. Chaim, Aldeamentos indígenas..., 87-89; 94.
} 
insistir na necessidade de utilizar-se o indígena para a ocupação efetiva do território". 44

A intenção de explorar a riqueza da terra pela extração mineral e depois a formação de extensas fazendas de gado tiveram nas populações indígenas um obstáculo natural. Os conflitos gerados nestes encontros por vezes terminavam em baixas humanas de ambos os lados, resultado que a Coroa desejava evitar. Desse contexto surgem as ordens metropolitanas de fundação de aldeamentos como alternativa para se evitar "males maiores", resultantes das perdas do colonizador e do indígena. Por outro lado, essa política tornava-se um dispositivo a ser usado para facilitar a pacificação de povos indígenas e desobstruir a via expansionista percorrida pelos colonizadores em suas excursões pelo vasto território goiano. ${ }^{45}$

Dessa forma, com D. Marcos de Noronha, iniciam-se as atividades de redução dos povos indígenas hostis, apoiados pelos sertanistas financiados com recursos arrecadados nos distintos arraiais existentes na Capitania. Todavia, a política dos aldeamentos evidencia-se pela descontinuidade com que se efetivava. Se na década de 1750 houve a instalação das primeiras unidades, ${ }^{46}$ no período seguinte houve um abandono dos aldeamentos com o retorno da ação ofensiva como marca dos contatos entre colonizadores e indígenas. Apenas a partir do final da década de 1770, tem-se "o revigoramento da política de pacificação e integração do índio através desses núcleos", 47 já no governo de D. José de Almeida Vasconcelos de Soveral e Carvalho, demarcando a segunda fase da política de aldeamentos.

Imbuído da filosofia pombalina, coube a José de Almeida Vasconcelos de Soveral e Carvalho deixar a capital Vila Boa, no início de 1773, para conhecer os arraiais da capitania de Goiás, em atendimento às obrigações que um governador deveria cumprir: visitar "pessoalmente tudo quanto se compreende de mais importante no distrito de sua jurisdição"48 para exercer um bom governo.

\footnotetext{
${ }^{44}$ Chaim, Aldeamentos indígenas..., 94.

${ }^{45}$ Chaim, Aldeamentos indígenas..., 104.

${ }^{46}$ Chaim, Aldeamentos indígenas..., 113-129.

${ }^{47}$ Chaim, Aldeamentos indígenas..., 110.

48 José P. M. de Alencastre, "Anais da Província de Goiás-1863", (Convênio SUDECO/Governo de Goiás, Goiânia, 1979), 174.
} 
Segundo Palacin ${ }^{49}$ o interesse do governador era instigado em virtude das circunstâncias "decadentes" em que se encontrava a Capitania naquele momento: declínio da mineração, agravado pelos rigores da devassa (1763-65) contra o Conde de São Miguel, ex-governador da Capitania (1755-59), e todo o funcionalismo desde os primórdios da mineração, com sua sequela de confiscos, penhoras e falências em cadeia; as consequências da grande seca de 1773-75, e as chuvas torrenciais do ano seguinte. Todos esses fatores agravaram a situação da Capitania, principalmente da Capital, deixando-a em um estado de penúria e letargia. ${ }^{50}$

A solução para tão adversa circunstância encontrava-se na busca por novas jazidas de ouro e na liberdade e "civilização" indígena, "uma força viva para a ocupação e desenvolvimento do Brasil, e a segurança das fronteiras". ${ }^{51}$ Os moradores, incentivados a organizarem novas bandeiras, deviam participar com mantimentos, soldados, escravos ou ferramentas visando a exploração dos vastos sertões "incultos e desconhecidos", principalmente os do "Vale do Araguaia, onde se supunha, com razão, deverem existir os ricos mananciais do ambicionado metal". ${ }^{52}$

Quatro expedições foram organizadas, duas delas eram de Traíras e tinham como destino o Araguaia com a finalidade de encontrar o ouro dos Martírios.

No lapso de tempo ocorrido entre a primeira e a segunda bandeiras organizadas pelos moradores de Traíras, José de Vasconcelos receberia recomendações da Coroa Portuguesa para "cuidar com particular empenho da redução e pacificação dos índios. [...] Chamar à paz e ao governo da civilização carajás, e javaés, fundar uma povoação na margem do Araguaia, e preparar o futuro da navegação deste rio." ${ }^{53}$ Desde então, esse foi o projeto principal do governador, ao qual seu nome definitivamente esteve vinculado. ${ }^{54}$

Organizou-se então, em junho de 1775, a expedição para a conquista pacífica dos Karajá e Javaé sob a responsabilidade do alferes José Pinto da Fonseca "homem

\footnotetext{
49 Palacin, "Política pombalina em Goiás...".

50 Palacin, "Política pombalina em Goiás...", 284.

51 Palacin, "Política pombalina em Goiás...", 272-3.

52 Alencastre, "Anais da Província de Goiás-1863"..., 193.

53 Alencastre, "Anais da Província de Goiás-1863"..., 196.

54 Palacin, "Política pombalina em Goiás...", 284-5.
} 
resoluto, prudente, e com a precisa inteligência para bem desempenhá-la", ${ }^{55}$ depois da malograda expedição de José Machado de Oliveira. Essa, partindo de Vila Boa em 1774, buscava encontrar às margens do Araguaia o tão procurado lugar dos Martírios. Porém, José Machado de Oliveira chegou apenas no extremo sul da ilha, encontrando na região os Iny (Karajá e Javaé).

O receio de prosseguir em meio a aldeias indígenas numerosas o fez retornar à Vila Boa apenas com as promessas da amizade indígena, informação que contribuiria para fomentar o interesse do governador José de Vasconcelos em reorganizar outra expedição com vistas a encontrar o tão encantado e prodigioso lugar.

A carta, datada de 2 de agosto de $1775,{ }^{56}$ remete, por um lado, aos acontecimentos vivenciados pelos integrantes da segunda bandeira, chefiada por José Pinto da Fonseca, às margens do Araguaia quando os sertanistas excursionam pela Ilha do Bananal em busca do ouro dos Martírios e se depararam com os povos indígenas Iny (Karajá e Javaé). Por outro lado, aponta para o primeiro documento histórico que registra o contato entre Javaé e colonizadores no final do século XVIII, assumindo um lugar privilegiado na historiografia regional concernente aos contatos entre indígenas e não indígenas no Vale do Araguaia. ${ }^{57}$ Retomar os contatos "eternizados" na carta e seus desdobramentos no contexto da política pombalina de 1775, na Capitania de Goiás, possibilita cotejá-la com a memória histórica dos Javaé a respeito dos mesmos acontecimentos.

\section{CONTATOS INTERÉTNICOS NA PERSPECTIVA JAVAÉ}

\footnotetext{
55 Alencastre, "Anais da Província de Goiás-1863"..., 196-7.

56 José P. Fonseca, "Cópia da carta que 0 alferes José Pinto da Fonseca escreveu ao Exmo. General de Goyazes, dando-lhe conta do descobrimento de duas nações de indios, dirigida do sitio onde portou", Revista Trimensal de História e Geographia ou Jornal do Instituto Historico e Geographico Brasileiro VIII, (2ª . edição, 1867), 376-390.

${ }^{57}$ Alencastre, "Anais da Província de Goiás-1863"...; Chaim, Aldeamentos indígenas...; Toral, "Cosmologia e sociedade Karajá"...; Juciene Ricarte Apolinário, Os Akroá e outros povos indígenas nas Fronteiras do Sertão: Políticas indígena e indigenista no norte da capitania de Goiás - Século XVIII (Goiânia: Kelps, 2006); Thiago Cancellier Dias, "Contatos e desacatos: os línguas na fronteira entre sociedade colonizadora e indígenas (1740 a 1889) - Goiás", Espaço Ameríndio 7, 1 (jul./dez.2013): 205-226; Thiago Cancelier Dias, "O língua e as línguas: aldeamentos e mestiçagens entre manejos de mundo indígenas em Goiás (1721-1832)", (Tese de doutorado, Universidade Federal de Goiás, Faculdade de História (FH), Programa de Pós-Graduação em História, Goiânia, 2017); Karasch, Before Brasília..., 45-69; André Egidio Pin. História do povo Javaé (Iny) e sua relação com as políticas indigenistas: da colonização ao Estado brasileiro (1775-1960). (Dissertação de Mestrado, Programa de PósGraduação em História - UFG, Goiânia, 2014).
} 
Na carta consta o "descobrimento" de dois povos indígenas: Karajá e Javaé, pelas excursões incentivadas por José de Almeida para estabelecer acordos de paz com os povos indígenas da região do Vale do Araguaia, mais especificamente da grande ilha (de Sant'Anna) habitada por muitos povos indígenas, sendo os principais os Karajá (seis grandes aldeias) e os Javaé (três aldeias). Após vinte e quatro dias de viagem, a bandeira retorna a um lugar que os colonizadores tinham estado um ano antes, na primeira bandeira de Traíras, liderada pelo capitão José Machado de Oliveira, ocasião em que comunicara com os indígenas e colocaram o nome do lugar de Bananal.

A análise dos fatos sob a perspectiva do Governo da Capitania de Goiás no século XVIII privilegia a narrativa oficial e colonizadora dos acontecimentos relativos à "conquista" dos Iny (Karajá e Javaé). Porém, o objetivo de demonstrar mudanças na condução da política indígenista (antes violenta, agora pacífica) expõe aspectos da memória indígena permeada por lembranças dolorosas, oriundas dos contatos violentos com sertanistas em períodos anteriores. Os desdobramentos dessas lembranças teriam como fundamento principal o receio dos Iny em entrar em contato com os não-indígenas e sofrer novamente a violência a que foram submetidos.

Encontrar dados dessa memória indígena em um documento oficial é importante em uma pesquisa de cunho decolonial, pois permite uma compreensão da perspectiva Iny em relação aos fatos analisados. Por outro lado, como estes mesmos acontecimentos ficaram registrados na memória dos Javaé? Em que ocasião teria ocorridos os primeiros contatos com os não indígenas nesse período? Qual teria sido a natureza desses contatos?

Na narrativa Javaé, a ocupação colonial constituía-se em uma invasão anunciada por um "presságio negativo sobre os brancos" (Tori dada), ou seja, pelo aparecimento de um pássaro novo na região, o wòòtòkò, uma espécie de pomba, desconhecida anteriormente. Os Torihuhu ("os Tori antigos" ou primeiros bandeirantes) são responsáveis, na memória Javaé, pelo extermínio do povo Torohoni, 
um povo que habitava a região da atual aldeia Canoanã e falava o Iny Rybè. ${ }^{58}$ Segundo essa história, apareceu

uma cabeça humana rolando e pulando na aldeia Kanõanõ, como uma bola, enquanto olhava a todos de modo diferente e cantava uma música conhecida até hoje. $O$ fato foi interpretado como dada, um presságio de um acontecimento negativo, deixando o povo de Kanãonõ em pânico. Sempre que alguém tentava pegar a cabeça, ela desaparecia magicamente para reaparecer depois. O presságio foi confirmado com a chegada dos Torihuhu, portadores de espadas compridas com as quais decapitaram os Torohoni, exterminando toda a população de Kanõanõ, que por isso não deixou nenhum descendente entre os Javaé atuais. ${ }^{59}$

A anciã da aldeia Canoanã ${ }^{60}$, Ilha do Bananal, Formoso do Araguaia-TO, Nilda Mytara Javaé (1940-), guarda na memória histórias que sua mãe contava quando era pequena. Por não falar a língua portuguesa, embora a compreendesse, a conversa foi mediada por Sidney Iroana Javaé e traduzida por ele e também por Edilson Haburunatu Javaé, ambos estudantes do curso de Licenciatura em Educação Intercultural Indígena da UFG. Nilda Mytara Javaé narrou eventos dramáticos envolvendo os Torihuhu.

... ela contou que aqui era uma grande aldeia e que os bandeirantes vieram e atacar... atacar a aldeia e é... acabou com eles e muitos foram levados pras cidades... (Sidney Iroana Javaé, 2018).

Ela falou que... tinha muita gente, né, por isso que tem o pedaço de cerâmica, panela velha, né, panela de barro, tem pedaço de... mais ou menos um... um quilômetro quadrado que o povo morou, né? Depois que o povo morou aí vieram o... o Torihuhu, né, que ela falou que é homem branco... homem branco, né, que vieram com facão, com peso, na verdade era espada, né, que cortava o... cortava os criança, matava, na verdade, matava com... os índio com a espada, né? Aí na história dos índio fala que cortava, né? E mocado, e... o homem branco matou um mocado de gente, né, um mocado dos indígenas, né? Aí algumas pessoas correram no mato por causa de medo, pra não morrer, né? Por isso que, eles destruíram a... a aldeia indígena, né? Aí ela fala, depois ela falou que... quando pegava as crianças, quando chorava, quando carregava, eles matava, né? (Edilson Haburunatu Javaé, 2018).

\footnotetext{
${ }^{58}$ Rodrigues, "A caminhada de Tanyxiwé..., 71.

${ }^{59}$ Rodrigues, "A caminhada de Tanyxiwé...", 95.

${ }^{60}$ Pesquisa aprovada pelo Comitê de Ética em Pesquisa da UFG (CAAE: 60697215.7.0000.5083).
} 
Pondera-se que os eventos narrados acima correspondam ao período da expansão colonial quando outros povos foram exterminados pelos Torihuhu, que continuaram andando pela ilha até chegar a Marani Hãwa.

Marani Hãwa constituiu-se em um lugar referencial para a constituição cosmológica dos Javaé atuais, oriunda da contribuição de povos distintos que emergiram do Fundo das Águas em lugares diferentes. Com as transformações e dinâmicas produzidas pelos acontecimentos proporcionados pela saída desses povos do Berahatxi, muitos se concentraram ou conviveram na aldeia Marani Hãwa, um pólo irradiador de cultura. Por meio de casamentos, misturas e trocas culturais, relações eram forjadas dando origem à cultura Javaé atual.

Além de ser um lugar de irradiação cultural, essa aldeia também era respeitada e encantada, protegida com "algo como um círculo de poder mágico", que a refazia quando entrava em decadência, como no ataque dos Torihuhu. Mesmo protegida pelo Iòlò ${ }^{61}$ Tòlòra - o grande líder ancestral que deu origem aos Javaé atuais, cuja prática política pautava-se em atitudes nobres e pacificadoras -, os "brancos muito antigos" atacaram-na, investindo contra toda a sua população, incluindo as crianças. Muitos morreram e alguns conseguiram fugir. Tempos depois, o próprio Iòlò Tòlòra, que havia sido ferido durante o ataque por manaju wyhy ("flechas de pedra" ou balas de armas de fogo), retornou para Marani Hãwa com outros sobreviventes e a refez.

Embora não haja referência à temporalidade na narrativa Javaé ${ }^{62}$, desde o início do século XVII, os Iny eram aprisionados e levados para o litoral, tal como vimos anteriormente, ao descrever os acontecimentos ocorridos por ocasião da bandeira de Martim Rodrigues Tenório de Aguilar (1608-1613). Na Carta de José Pinto da Fonseca, ele registra o temor dos Karajá em contatar os não indígenas, em virtude de horríveis acontecimentos ocorridos anteriormente, durante a expedição de Antônio Pires de Campos, mais de vinte anos antes.

\footnotetext{
61 Título de chefia transmitido hereditariamente a quem cabe a tarefa de conciliação e pacificação de conflitos, sendo o primeiro 0 grande líder pacifista Tòlòra.

62 Sobre a questão da temporalidade entre os povos indígenas ver os seguintes textos: Nazareno, "História, tempo e lugar..., 85-118 e Elias Nazareno; Ordália Cristina G. Araújo; Tamiris Maia G. Pereira, "Tempo, lugar e interculturalidade na perspectiva dos estudantes indígenas do curso de educação intercultural da UFG", Espaço Ameríndio 13, 1 (jan./jun., 2019): 87-113.
} 
As atrocidades cometidas por Pires de Campos contra os indígenas atingiram o extremo da violência. Tais expedições atacaram aldeias Iny no Vale do Araguaia, cujos temores e horrores estavam vivos na memória dos Karajá e Javaé no momento do contato com o Alferes José Pinto da Fonseca, não vinte, mas trinta anos antes. ${ }^{63}$ Embora houvesse a reminiscência de toda essa violência, os "termos de vassalagem" das lideranças Karajá (Alve Nona) e Javaé (Acabedú-ani) foram assinados por José Pinto da Fonseca e remetido ao capitão-general José de Almeida. O termo de Acabedú-ani ficou assim registrado:

Na minha terra chegou tua gente, senhor, dando para nós muitas coisas que estimamos, e um papel que para nós fala coisas boas. Teu filho diz que és de coração bom, e que o grande pai dos brancos quer tomar cuidado pela gente da nossa pele; dize tu a eles que sejam sempre nossos camaradas. Quando teu filho for para tua terra, eu mando meu filho visitar tua casa, e espero, senhor, que tu o mandes voltar, para que meu coração não fique doente. Ilha de Santana, $1^{\circ}$ de agosto de 1775 . Aboé-noná. Acabedú-ani.

A legitimação do acordo de paz com os indígenas era feito pelo lado do colonizador, mediante a assinatura dos representantes do governador da Capitania, no "termo de vassalagem", redigido por um escrivão da bandeira sob as ordens do alferes. O termo constitui-se, portanto, em um dispositivo que assegurava ao colonizador a apropriação, pela conquista, do território indígena, visando a efetivação de um projeto de expansão e ocupação, assegurada pelo acordo "pacífico" estabelecido com os povos Karajá e Javaé.

Desde então, os Javaé tiveram sua trajetória transformada pelos contatos com a sociedade não indígena, sendo colocados pelos colonizadores, bandeiristas e missionários em uma posição de inferioridade (diferentes, infantilizados e incivilizados), carentes, portanto, do auxílio do colonizador para inserção no mundo dos não indígenas. Até suas aldeias foram nomeadas segundo a língua do colonizador. À aldeia Karajá, considerada a principal, recebeu a denominação colonial de São Pedro do Sul e às aldeias Javaé (quatro) de Ponte de Lima, Angeja, Lavradio e Anadia. ${ }^{64}$

\footnotetext{
63 Alencastre, "Anais da Província de Goiás-1863"..., 198

64 Alencastre, "Anais da Província de Goiás-1863"..., 204.
} 
No ano seguinte, em 1776, foi enviada uma expedição composta por 135 pessoas para fundar o primeiro presídio da Ilha do Bananal, o presídio ${ }^{65}$ São Pedro do Sul. $^{66}$

Também em 1776, morreria o "maioral" dos Javaé, Acabedú-ani. A escolha do futuro "maioral" constituía-se em um acontecimento de total interesse dos colonizadores, cabendo até mesmo uma interferência na escolha do futuro cacique. O escolhido foi um indígena sugerido pelo governador, fato que representava a concretização dos planos que José de Almeida Vasconcelos estabelecera desde 1773.

Nos momentos finais do seu governo, em 1778, José de Almeida Vasconcelos faria recomendações ao seu sucessor no tocante ao tratamento a ser dispensado aos indígenas, sobretudo em relação à conquista efetivada três anos antes. Na perspectiva do governador, os próprios indígenas teriam ido à Vila Boa com seus arcos, flechas, lanças e penachos pedir perdão pelos insultos provocados a ele e aos não indígenas, além de "renovar-me em nome dos seus maiorais a promessa da aliança, que aqueles tinham jurado, protestando a devida sujeição a S. M". ${ }^{67}$

Esse "grande" feito deveria ser preservado, tendo em vista que se tratava de uma conquista de oito a dez mil almas entre "carajás, javaés e xambioaz". Para José de Vasconcelos, a comunicação entre indígenas e não indígenas por meio da relação de trocas efetivas (objetos indígenas por facas, tesouras, miçangas, vestuário) permitia assenhorear-se do ânimo dos indígenas "mediante uma regular educação" que produziria, como consequência, "homens úteis à religião e ao Estado". ${ }^{6}$ Contudo, o que estava por trás de todas as tentativas de pacificação indígena era expansão colonial viabilizada pela busca de jazidas de ouro. ${ }^{69}$

Após o fim de seu governo em 1778 e consequente retorno para Portugal, José de Almeida Vasconcelos, defensor da política pombalina, levou consigo cinco

\footnotetext{
65 Como extensão da política colonizadora ibérica nas colônias africanas e latino-americanas, os presídios, no Brasil, representavam a ação colonizadora. No Norte do então estado de Goiás, a construção destes destacamentos militares surgiu da necessidade de implementar a navegação do rio Araguaia e o povoamento da região, política oficial praticada principalmente a partir de 1850, ainda que outros presídios já tivessem antes sido construídos (São João das Duas Barras - 1802 e Santa Maria do Araguaia - 1812). Inicialmente, essas pequenas colônias eram construídas com recursos do governo para fixar moradores na região. Porém, com o passar do tempo, elas deveriam se estruturar para se autossustentar Cf. Elianda Figueiredo Arantes Tiballi, "A expansão do povoamento em Goiás - Século XIX", (Dissertação de Mestrado, Instituto de Ciências Humanas e Letras da Universidade Federal de Goiás, Goiânia, 1991), 80-86.

${ }^{66}$ Alencastre, "Anais da Província de Goiás-1863" , 204-5.

${ }^{67}$ Alencastre, "Anais da Província de Goiás-1863" , 277-8.

68 Alencastre, "Anais da Província de Goiás-1863", 230.

${ }^{69}$ Alencastre, "Anais da Província de Goiás-1863", 230-1.
} 
indígenas representantes dos povos Akroá, Xacriabá, Karajá, Kaiapó, e também Javaé. ${ }^{70}$ Sua intenção constituía-se em "educar, nas escolas e/ou seminários portugueses algumas lideranças indígenas para, posteriormente, enviá-los aos aldeamentos objetivando que colaborassem no processo de 'civilização' dos indígenas aldeados".71

\section{CONSIDERAÇÕES FINAIS}

Em 1780, no governo de Luis da Cunha Menezes, os setecentos Javaé e Karajá de Nova Beira foram transferidos para o aldeamento de São José de Mossâmedes com a finalidade de aumentar sua população, "provocando, em consequência, o declínio de um princípio de povoado que pela sua situação geográfica prometia prosperar" (CHAIM, 1983, p. 123). Muitos já haviam aprendido "officios e se mostraram habeis, principalmente as mulheres para coser e fiar" (SOUSA, 1872, p. 460). Provavelmente, também já haviam sido submetidos às ações evangelizadoras desses lugares destinados a civilizar.

Surtos de sarampo seguidos de mortes, transferências, maus tratos e falta de subsídios oficiais para manutenção dos aldeamentos desembocaram no declínio do aldeamento de São José de Mossâmedes. Os indígenas sobreviventes foram transferidos para Salinas, em 1788, ou retornaram para suas aldeias, no início do século XIX.

Circunstâncias devastadoras como essas produziram nos Javaé um receio de contatar os não indígenas no decorrer do século XIX, levando-os a assumir uma postura eminentemente isolacionista, ao buscar refúgio no interior da Ilha do Bananal.

Tanto no momento forjado do acordo de paz quanto nos aldeamentos (em virtude das duras condições a que os Javaé foram neles submetidos), a postura intercultural de resistência se evidenciou. $\mathrm{Na}$ primeira, por reconhecerem e afirmarem serem donos das terras que o Rei de Portugal almejava explorar e, na

\footnotetext{
70 Oficio do [barão de Mossâmedes], ex-governador e capitão-general de Goiás, José Almeida de Vasconcelos [de Soveral e Carvalho], ao [secretário de estado da Marinha e Ultramar], Martinho de Melo e Castro, 1778, Dezembro, 20, Lisboa AHU_CU_008, Cx. 30, D. 1957.

${ }^{71}$ Apolinário, Os Akroá e outros povos indígenas nas Fronteiras do Sertão..., 213.
} 
segunda, pelo isolamento no interior da Ilha do Bananal ao longo do século XIX, buscando fugir dos maus tratos a que foram submetidos nos aldeamentos.

Porém, já no final deste mesmo século, vários agentes sociais começaram a visitar as aldeias Javaé (representantes do governo provincial, lideranças religiosas católicas e protestantes, etnólogos, comerciantes e moradores do Alto Araguaia), resultando, em 1950, na saída definitiva destes do interior da ilha para estabelecer contatos com os regionais, ${ }^{72}$ retomando o contato com os não indígenas.

Mais recentemente, sobretudo a partir dos estudos antropológicos ${ }^{73} \mathrm{e}$ historiográficos, ${ }^{74}$ o povo Javaé, representados principalmente pelos estudantes e egressos do Curso de Licenciatura em Educação Intercultural Indígena da Universidade Federal de Goiás, tem empreendido práticas de visibilização nos meios acadêmicos e sociais pautadas pela concepção autodeterminada de povo único, com aspectos identitários, cosmológicos e linguísticos próprios e não derivados dos Karajá, como comumente eram retratados em parte da literatura antropológica do século XX.

Assim, esse artigo cumpre uma função ética e política de elucidar, nos estudos historiográficos e antropológicos, pistas que, tomadas em conjunto, permite a construção histórica do protagonismo e resistência Javaé no decorrer do projeto colonizador numa região de fronteira como é a do Vale do Araguaia.

\section{REFERENCIAS}

Ailton Krenak, "O eterno retorno do encontro". In: Adauto Novaes (org.), A Outra Margem do Ocidente (São Paulo, Companhia das Letras, 1999), 25-27.

\footnotetext{
72 Toral, "Cosmologia e sociedade Karajá"...

${ }^{73}$ Rodrigues, "A caminhada de Tanyxiwé....".

74 Ordália Cristina Gonçalves Araújo, "Os Javaé e o protestantismo: salvação e resistência (1896-1937)" (Tese de doutorado, Universidade Federal de Goiás, Programa de Pós-Graduação em História, Universidade Federal de Goiás, Goiânia-GO, Brasil, 2019); Nascimento, Protagonismo indígena na capitania de Goiás...; Luciana Leite Silva, "Aprendizagem histórica intercultural a partir dos contextos educacionais indígenas e não indígenas" (Tese de doutorado, Universidade Federal de Goiás, Programa de Pós-Graduação em História, Goiânia-GO, Brasil, 2019); Tamiris Maia Gonçalves Pereira, "Saberes e fazeres Javaé: estudo das práticas tradicionais alimentares indígenas, da década de 1990 a 2020", (Tese de doutorado, Universidade Federal de Goiás, Programa de Pós-Graduação em História, Goiânia-GO, Brasil, 2020).
} 
André Egidio Pin. "História do povo Javaé (Iny) e sua relação com as políticas indigenistas: da colonização ao Estado brasileiro (1775-1960)". (Dissertação de Mestrado, Programa de PósGraduação em História - UFG, Goiânia, 2014).

André Toral, "Cosmologia e sociedade Karajá", (Dissertação de Mestrado, Programa de Pós-Graduação em Antropologia Social, Museu Nacional, Universidade Federal do Rio de Janeiro, Rio de Janeiro, 1992).

Andréa Doré, "América Peruana e Oceanus Peruvianus: uma outra cartografia para o Novo Mundo", 20 (Outubro 2014): 1-22.

Aníbal Quijano, "Colonialidade do poder e classificação social", In: SANTOS, Boaventura Souza; MENESES, Maria Paula. (Org.). Epistemologia do Sul. São Paulo: Cortez, 2010.

Beatriz Perrone-Moisés, "Índios livres e índios escravos: os princípios da legislação indigenista do período colonial (séculos XVI a XVIII)", In: Manuela Carneiro da Cunha (Org.) História dos índios no Brasil (São Paulo: Companhia das Letras/Sec. Mun. de Cultura/FAPESP, 1992) 115-132.

Carlos Christian Della Giustina, "Degradação e Conservação do Cerrado: uma história ambiental do estado de Goiás" (Brasília, s/e., 2013), 92.

Catherine Walsh (Org), "Pedagogías decoloniales: Prácticas insurgentes de resistir, (re)existir y (re)vivir", (Quito-Ecuador: Ediciones Abya-Yala. Serie Pensamiento decolonial, 2013), 23-68.

Dutra e Silva, Sandro, "Challenging the Environmental History of the Cerrado: Science, Biodiversity and Politics on the Brazilian Agricultural Frontier", Historia Ambiental Latinoamericana Y Caribeña (HALAC) $10 \quad$ (1), 82-116. https://doi.org/10.32991/2237-2717.2020v10i1.p82-116.

Dutra e Silva, Sandro; Barbosa, Altair Sales, "Paisagens e fronteiras do Cerrado: ciência, biodiversidade e expansão agrícola nos chapadões centrais do Brasil", Estudos Ibero-Americanos 6, 1 (jan.-abr. 2020): 1-18.

Elianda Figueiredo Arantes Tiballi, "A expansão do povoamento em Goiás - Século XIX", (Dissertação de Mestrado, Instituto de Ciências Humanas e Letras da Universidade Federal de Goiás, Goiânia, 1991).

Elias, Nazareno, "História, tempo e lugar entre o povo indígena Bero Biawa Mahãdu (Javaé): a partir da interculturalidade crítica, da decolonialidade e do enfoque enactivo", In: Marcos de Jesus Oliveira (Org.), Direitos humanos e pluriversalidade: conexões temáticas, (Curitiba: Editora Prismas Ltda, 2017), 85-118.

Elias Nazareno; Ordália Cristina G. Araújo; Tamiris Maia G. Pereira, "Tempo, lugar e interculturalidade na perspectiva dos estudantes indígenas do curso de educação intercultural da UFG", Espaço Ameríndio 13, 1 (jan./jun., 2019): 87-113. 
Fritz Krause. "Nos sertões do Brasil", Revista do Arquivo Municipal 73-74 (1940-43): 274-5.

José P. Fonseca, "Cópia da carta que o alferes José Pinto da Fonseca escreveu ao Exmo. General de Goyazes, dando-lhe conta do descobrimento de duas nações de indios, dirigida do sitio onde portou", Revista Trimensal de História e Geographia ou Jornal do Instituto Historico e Geographico Brasileiro VIII, (2a . edição, 1867), 376-390.

José P. M. de Alencastre, "Anais da Província de Goiás-1863", (Convênio SUDECO/Governo de Goiás, Goiânia, 1979).

Juciene Ricarte Apolinário, Os Akroá e outros povos indígenas nas Fronteiras do Sertão: Políticas indígena e indigenista no norte da capitania de Goiás - Século XVIII (Goiânia: Kelps, 2006).

Lázaro Lopes Rosário Tapuio, "A importância do rio Javaé para o povo Javaé", (Projeto Extraexcolar, Universidade Federal de Goiás, Goiânia, 2011).

Luciana Leite Silva, "Aprendizagem histórica intercultural a partir dos contextos educacionais indígenas e não indígenas" (Tese de doutorado, Universidade Federal de Goiás, Programa de Pós-Graduação em História, Goiânia-GO, Brasil, 2019).

Luís Palacin, "Política pombalina em Goiás - contrastes", Revista do ICHL (1982): 271290.

Luiz Antonio da Silva e Sousa, "Memoria sobre o descobrimento, governo, população, e cousas mais notaveis da Capitania de Goyaz", Revista Trimensal de Historia e Geographia ou Jornal do Instituto Historico e Geographico Brasileiro XII $\left(4^{\circ}\right.$ trimestre de 1849, $2^{\text {a }}$. edição 1872): 429-510.

Manoel Rodrigues Ferreira, O mistério do ouro dos martírios: desvendando o grande segrêdo das bandeiras paulistas (São Paulo, Editora Biblos, 1960).

Manoel Rodrigues Ferreira, As bandeiras do Paraupava (São Paulo, Prefeitura Municipal, 1977).

Manuela Carneiro da Cunha, Introdução a uma história indígena, In: História dos índios no Brasil (São Paulo: Cia das Letras, Secretaria Municipal de Cultural: FAPESP, 1992), 9-24.

Maria do Socorro Pimentel da Silva, "As línguas indígenas na escola: da desvalorização à revitalização, Signótica 18, 2, (jul./dez. 2006): 381-395.

Maria do Socorro Pimentel da Silva, Impactos da educação na vitalidade patrimônio epistêmico Iny, (Goiânia, Kelps, 2015): 14.

Marivone Matos Chaim, Aldeamentos indígenas: Goiás (1749-1811) (São Paulo, Nobel, 1983). 
Mary Karasch, Catequese e cativeiro: política indigenista em Goiás, 1789-1889. In: Manuela Carneiro da Cunha, História dos índios no Brasil (São Paulo, Companhia das Letras, Secretaria Municipal de Cultura/FAPESP, 1992), 397-412.

Mary Karasch, Before Brasília: Frontier Life in Central Brazil (University of New York Press, 2016), 45-69.

Nathalia Cunha Polese, "Crianças indígenas da aldeia Canuanã (Formoso do Araguaia TO): relação entre cultura, infância e educação", (Dissertação de Mestrado, Universidade do Estado de Minas Gerais, Programa de Pós-graduação em Educação, 2014).

Ordália Cristina Gonçalves Araújo, "Os Javaé e o protestantismo: salvação e resistência (1896-1937)" (Tese de doutorado, Universidade Federal de Goiás, Programa de PósGraduação em História, Universidade Federal de Goiás, Goiânia-GO, Brasil, 2019).

Patrícia de Mendonça Rodrigues, "O povo do meio: uma paradoxal mistura pura", Revista de Estudos e Pesquisas 1, 1, (jul. 2004): 11-63.

Patrícia de Mendonça Rodrigues, "De corpo aberto: o poder tecnológico dos nãoíndios no mito e na cosmologia Javaé", Habitus 3, 1 (jan./jun. 2005): 125-143.

Patrícia de Mendonça Rodrigues, "Vida Cerimonial e luto entre os Javaé", Revista de Estudos e Pesquisas 3, 1/2 (jul./dez. 2006): 107-131.

Patrícia de Mendonça Rodrigues, "A caminhada de Tanyxiwé: uma teoria Javaé da História", (Tese de doutorado, Chicago, 2008).

Patrícia Emanuelle Nascimento Protagonismo indígena na capitania de Goiás e suas estratégias e atuações frente às políticas indigenistas no século XVIII. 2019. 268 f. Tese (Doutorado em História) - Universidade Federal de Goiás, Goiânia, 2019.

Paulo Bertran, "As primeiras descobertas dos cerrados centrais", Revista Humanidades 8, 2 (1992): 229-237.

Paulo Bertran, História da terra e do homem no Planalto Central. Eco-história do Distrito Federal: do indígena ao colonizador (Brasília, Editora Verano, 2000).

Stephen Grant Baines, O xamanismo como história: censuras e memórias da pacificação Waimiri-Atroari. In: Bruce Albert; Alcida Rita Ramos, Pacificando o branco: cosmologias do contato no Norte-Amazônico (São Paulo, Ed. UNESP, Imprensa Oficial do Estado, 2002), 311-345.

Tamiris Maia Gonçalves Pereira, "Saberes e fazeres Javaé: estudo das práticas tradicionais alimentares indígenas, da década de 1990 a 2020", (Tese de doutorado, Universidade Federal de Goiás, Programa de Pós-Graduação em História, Goiânia-GO, Brasil, 2020). 
Thiago Cancellier Dias, "Contatos e desacatos: os línguas na fronteira entre sociedade colonizadora e indígenas (1740 a 1889) - Goiás", Espaço Ameríndio 7, 1 (jul./dez.2013): 205-226.

Thiago Cancelier Dias, "O língua e as línguas: aldeamentos e mestiçagens entre manejos de mundo indígenas em Goiás (1721-1832)", (Tese de doutorado, Universidade Federal de Goiás, Faculdade de História (FH), Programa de Pós-Graduação em História, Goiânia, 2017).

Walter Mignolo, Desobediência epistêmica: retórica de la modernidad, lógica de la colonialidad y gramática de la descolonialidade. Ediciones del Signo, Argentina, 2010.

\title{
Interethnic contacts in Araguaia Valley: INY and colonizers between the 16 th and 20 th centuries
}

\begin{abstract}
This article investigates, based on the historiographical and anthropological literature, the history of the contacts established between the Iny during the colonization of the Brazilian territory, with emphasis on the way the Javaé interacted with the colonizers during the territorial occupation of the central region of Brazil, between the 16th and 20th centuries. Based on the expeditions that crossed "os sertões of Paraupava", the history of interethnic contacts between the Javaé and the colonizers was analyzed, seeking, from a documentary and bibliographical analysis, the decolonial perspective, the Javaé point of view inserted in this literature. Thus, it is expected to contribute to the understanding of the protagonism and isolationist posture of these people in the interior of Bananal Island in practically the entire 19th century as a resistance to these contacts.
\end{abstract}

Keywords: interethnic contacts; Araguaia River; Javaé people.

Recibido: 30/03/2020 Aprobado: 25/05/2020 